\title{
Forward Kinematics and Performance Test of a Six Degree of Freedom Articulated Robotic Arm
}

\author{
Nang Yi Phoo Thet ${ }^{1}$, Myint Thein ${ }^{2}$, Htay Htay Win ${ }^{3}$ and Aung Ko Latt ${ }^{4}$ \\ Research Scholar ${ }^{1}$, Professor $^{2-3}$ and Associate Professor ${ }^{4}$ \\ 1-2-3-4 Department of Mechanical Engineering \\ Mandalay Technological University \\ Mandalay \\ Myanmar
}

\begin{abstract}
In this research, the performance test of a six degree of freedom (DOF) articulated robotic arm is presented based on the kinematic analysis. The kinematics is derived based on the Denavit-Hartenberg (DH) representation of the robotic arm. The simulation of robotic kinematics is performed by RoboAnalyzer simulation software. The use of RoboAnalyzer simulation software can make the modeling and analysis of serial robots more flexible. The total workspace of a six DOF robotic arm $302.5 \times 302.5 \times 452.5 \mathrm{~mm}$ to carry a maximum payload of $100 \mathrm{~g}$ is used for painting operation. A simple painting task to paint a plane on the wall is carried out in order to get the kinematics models of the robotic arm. Twelve points of movement are studied for the forward kinematic modeling. Forward kinematics equations are derived theoretically and results are compared with RoboAnalyzer simulation software. Finally, simulation and performance tests, including the position of the robotic end-effector are presented below.
\end{abstract}

Key Words: Degree of freedom, End effector, Kinematics, Position, Robotic Arm.

\section{INTRODUCTION}

The Robot Institute of America designates a robot as "a reprogrammable, multifunctional manipulator designed to move material, parts, tools, or specialized devices through various programmed motions for the performance of a variety of tasks" [5]. The basic components of a robot system are the mechanical linkage which consists of links, joints and end effector. For a six DOF robotic arm, the first three links and joints form the arm and the last three mutually in intersecting joints made a wrist. The end effector is a part attached at the end of the manipulator. Specialized tools like the painting tool attached to the end of the manipulator arm for performing tasks are also considered as end effector [4].

This research discusses forward kinematics and simulation of a six degree of freedom (DOF) articulated robotic arm using RoboAnalyzer simulation software and testing performance of robotic arm for painting process. Forward kinematics equations are derived theoretically and results are compared with RoboAnalyzer simulation software. Finally simulation of the robotic arm using RoboAnalyzer was carried out and the results of performance test are presented below.

\section{ROBOT KINEMATICS MODEL}

Robotic arm kinematics deals with the analytical study of the geometry of motion of a robot arm with respect to a fixed reference coordinate system as a function of time without regard to the forces that cause the motion [10]. There are two types of kinematic analysis problems: forward kinematics and inverse kinematics. In this research, the homogeneous transformations and Denavit-Hartenberg (DH) representation of robotic arm are used to solve forward and inverse kinematics problems of manipulator. DH parameters for the robotic arm are listed in Table 1.

Table 1. DH parameters of a six DOF robotic arm

\begin{tabular}{|c|c|c|c|c|}
\hline Link & $\begin{array}{c}\text { Link Length } \\
\left(\mathbf{a}_{\mathbf{i}}\right),(\mathbf{m m})\end{array}$ & $\begin{array}{c}\text { Joint Distance } \\
\left(\mathbf{d}_{\mathbf{i}}\right),(\mathbf{m m})\end{array}$ & $\begin{array}{c}\text { Joint Twist } \\
\text { Angle }\left(\boldsymbol{\alpha}_{\mathbf{i}}\right) \\
(\mathbf{d e g r e e})\end{array}$ & $\begin{array}{c}\text { Joint Angle } \\
\left(\boldsymbol{\theta}_{\mathbf{i}}\right)\end{array}$ \\
\hline Link 1 & 0 & $d_{l}=150$ & 90 & $\theta_{1}$ \\
\hline
\end{tabular}


International Journal of Advances in Scientific Research and Engineering (ijasre), Vol 5 (12), December-2019

\begin{tabular}{|c|c|c|c|c|}
\hline Link 2 & $a_{2}=62.5$ & 0 & 0 & $\theta_{2}$ \\
\hline Link 3 & $a_{3}=62.5$ & 0 & 0 & $\theta_{3}$ \\
\hline Yaw & $a_{4}=62.5$ & 0 & 90 & $\theta_{4}$ \\
\hline Pitch & 0 & 0 & 90 & $\theta_{5}$ \\
\hline Roll & 0 & $d_{6}=115$ & 0 & $\theta_{6}$ \\
\hline
\end{tabular}

\subsection{The Work Piece for Painting Process}

This paper is focused on the kinematics of a simple painting process using a six DOF articulated robotic arm. Thus the work piece used is a simple small plane on the wall. The area of the plane is $180 \mathrm{~mm} \times 125 \mathrm{~mm}$ as shown in Figure 1. The work piece is not the main concern in this study, as it is just a dummy object used to carry out the end effector position. Twelve points of movement are studied for the forward kinematic modeling.

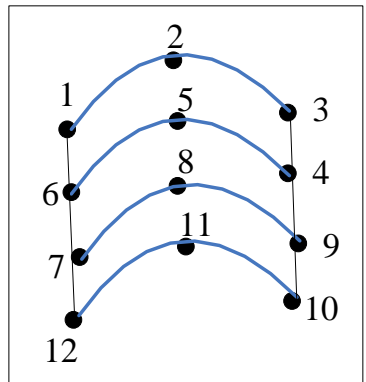

Figure 1. Dimension of the workpiece and the motion path of the end effector

\subsection{Forward Kinematics}

Forward kinematics refers to determine the values of position and orientation of the end effector, given the joint angles and link lengths of the robotic arm. DH parameters are used in this paper to describe the manipulator configuration. Simplified link coordinate diagram of a six DOF robotic arm is shown in Figure 2.

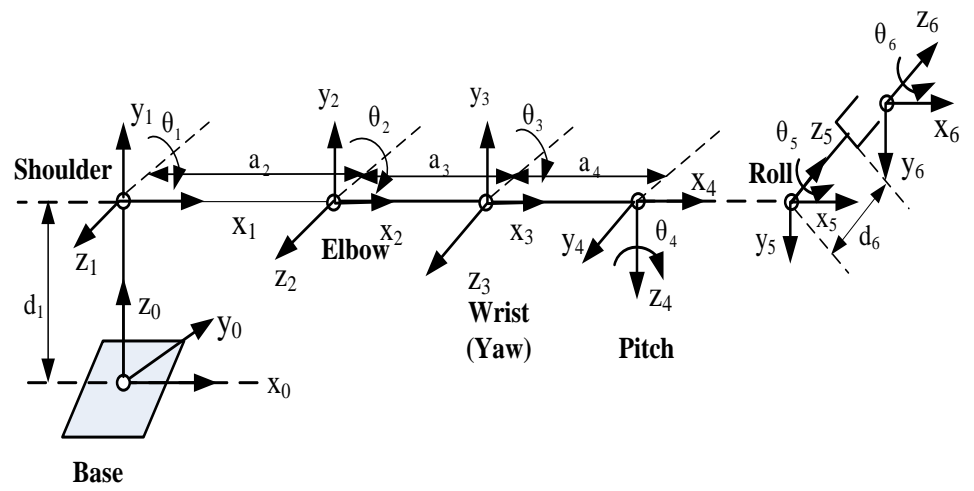

Figure 2. DH Coordinate frame assignment of a six DOF robotic arm

To calculate the values of position and orientation of each joint, the homogeneous transformation matrix is used. Since

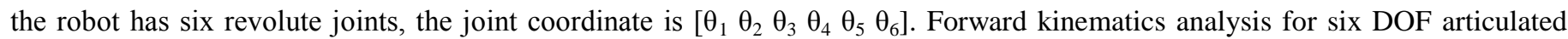
robot is determined as follows and desired input angles for painting process are shown in Table 2.

$$
\begin{aligned}
\mathrm{A}_{\mathrm{i}}^{\mathrm{i}-1} & =\left[\begin{array}{cccl}
\cos \theta_{\mathrm{i}} & -\sin \theta_{\mathrm{i}} \cos \alpha_{\mathrm{i}} & \sin \theta_{\mathrm{i}} \sin \alpha_{\mathrm{i}} & \mathrm{a}_{\mathrm{i}} \cos \theta_{\mathrm{i}} \\
\sin \theta_{\mathrm{i}} & \cos \theta_{\mathrm{i}} \cos \alpha_{\mathrm{i}} & -\cos \theta_{\mathrm{i}} \sin \alpha_{\mathrm{i}} & \mathrm{a}_{\mathrm{i}} \sin \theta_{\mathrm{i}} \\
0 & \sin \alpha_{\mathrm{i}} & \cos \alpha_{\mathrm{i}} & \mathrm{d}_{\mathrm{i}} \\
0 & 0 & 0 & 1
\end{array}\right] \\
{ }^{0} \mathrm{~T}_{6} & =\left[\begin{array}{llll}
\mathrm{n}_{\mathrm{x}} & \mathrm{o}_{\mathrm{x}} & \mathrm{a}_{\mathrm{x}} & \mathrm{P}_{\mathrm{x}} \\
\mathrm{n}_{\mathrm{y}} & \mathrm{o}_{\mathrm{y}} & \mathrm{a}_{\mathrm{y}} & \mathrm{P}_{\mathrm{y}} \\
\mathrm{n}_{\mathrm{z}} & \mathrm{o}_{\mathrm{z}} & \mathrm{a}_{\mathrm{z}} & \mathrm{P}_{\mathrm{z}} \\
0 & 0 & 0 & 1
\end{array}\right] \\
\mathrm{n}_{\mathrm{x}} & =\mathrm{C}_{1}\left(\mathrm{C}_{5} \mathrm{C}_{6} \mathrm{C}_{234}+\mathrm{S}_{6} \mathrm{~S}_{234}\right)+\mathrm{C}_{6} \mathrm{~S}_{1} \mathrm{~S}_{5}
\end{aligned}
$$


International Journal of Advances in Scientific Research and Engineering (ijasre), Vol 5 (12), December-2019

$$
\begin{aligned}
& \mathrm{n}_{\mathrm{y}}=\mathrm{S}_{1}\left(\mathrm{C}_{5} \mathrm{C}_{6} \mathrm{C}_{234}+\mathrm{S}_{6} \mathrm{~S}_{234}\right)-\mathrm{C}_{1} \mathrm{C}_{6} \mathrm{~S}_{5} \\
& \mathrm{n}_{\mathrm{z}}=\mathrm{C}_{5} \mathrm{C}_{6} \mathrm{~S}_{234}-\mathrm{C}_{234} \mathrm{~S}_{6} \\
& \mathrm{o}_{\mathrm{x}}=\mathrm{C}_{1}\left(-\mathrm{C}_{5} \mathrm{~S}_{6} \mathrm{C}_{234}+\mathrm{C}_{6} \mathrm{~S}_{234}\right)-\mathrm{S}_{1} \mathrm{~S}_{5} \mathrm{~S}_{6} \\
& \mathrm{o}_{\mathrm{y}}=\mathrm{S}_{1}\left(-\mathrm{C}_{5} \mathrm{~S}_{6} \mathrm{C}_{234}+\mathrm{C}_{6} \mathrm{~S}_{234}\right)+\mathrm{C}_{1} \mathrm{~S}_{5} \mathrm{~S}_{6} \\
& \mathrm{o}_{\mathrm{z}}=-\mathrm{C}_{5} \mathrm{~S}_{6} \mathrm{~S}_{234}-\mathrm{C}_{6} \mathrm{C}_{234} \\
& \mathrm{a}_{\mathrm{x}}=\mathrm{C}_{234} \mathrm{C}_{1} \mathrm{~S}_{5}-\mathrm{C}_{5} \mathrm{~S}_{1} \\
& \mathrm{a}_{\mathrm{y}}=\mathrm{C}_{234} \mathrm{~S}_{1} \mathrm{~S}_{5}+\mathrm{C}_{1} \mathrm{C}_{5} \\
& \mathrm{a}_{\mathrm{z}}=\mathrm{S}_{234} \mathrm{~S}_{5} \\
& \mathrm{P}_{\mathrm{x}}=\mathrm{C}_{1}\left(\mathrm{a}_{2} \mathrm{C}_{2}+\mathrm{a}_{4} \mathrm{C}_{234}+\mathrm{d}_{6} \mathrm{~S}_{5} \mathrm{C}_{234}+\mathrm{a}_{3} \mathrm{C}_{23}\right)-\mathrm{S}_{1} \mathrm{C}_{5} \mathrm{~d}_{6} \\
& \mathrm{P}_{\mathrm{y}}=\mathrm{S}_{1}\left(\mathrm{a}_{2} \mathrm{C}_{2}+\mathrm{a}_{4} \mathrm{C}_{234}+\mathrm{d}_{6} \mathrm{~S}_{5} \mathrm{C}_{234}+\mathrm{a}_{3} \mathrm{C}_{23}\right)+\mathrm{C}_{1} \mathrm{C}_{5} \mathrm{~d}_{6} \\
& \mathrm{P}_{\mathrm{z}}=\mathrm{d}_{1}+\mathrm{a}_{2} \mathrm{~S}_{2}+\mathrm{a}_{4} \mathrm{~S}_{234}+\mathrm{d}_{6} \mathrm{~S}_{5} \mathrm{~S}_{234}+\mathrm{a}_{3} \mathrm{~S}_{23}
\end{aligned}
$$

Where,

$$
\begin{aligned}
& \mathrm{C}_{1}=\cos \theta_{1}, \mathrm{~S}_{1}=\sin \theta_{1}, \mathrm{C}_{2}=\cos \theta_{2}, \mathrm{~S}_{2}=\sin \theta_{2}, \mathrm{C}_{23}=\cos \left(\theta_{2}+\theta_{3}\right), \mathrm{S}_{23}=\sin \left(\theta_{2}+\theta_{3}\right) \\
& \mathrm{C}_{5}=\cos \theta_{5}, \mathrm{~S}_{5}=\sin \theta_{5}, \mathrm{C}_{6}=\cos \theta_{6}, \mathrm{~S}_{6}=\sin \theta_{6}, \mathrm{C}_{234}=\cos \left(\theta_{2}+\theta_{3}+\theta_{4}\right), \mathrm{S}_{234}=\sin \left(\theta_{2}+\theta_{3}+\theta_{4}\right)
\end{aligned}
$$

Table 2. Desired input angles of a six DOF robotic arm for painting process

\begin{tabular}{|c|c|c|c|c|c|c|}
\hline \multirow{2}{*}{ Points } & \multicolumn{7}{|c|}{ Desired Input Angles (Degree) } \\
\cline { 2 - 7 } & $\boldsymbol{\theta}_{\mathbf{1}}$ & $\boldsymbol{\theta}_{\mathbf{2}}$ & $\boldsymbol{\theta}_{\mathbf{3}}$ & $\boldsymbol{\theta}_{\mathbf{4}}$ & $\boldsymbol{\theta}_{\mathbf{5}}$ & $\boldsymbol{\theta}_{\mathbf{6}}$ \\
\hline $\mathbf{1}$ & 80 & 40 & -40 & 10 & 90 & 90 \\
\hline $\mathbf{2}$ & 45 & 30 & 15 & -15 & 90 & 90 \\
\hline $\mathbf{3}$ & 12 & 50 & -40 & -5 & 90 & 90 \\
\hline $\mathbf{4}$ & 16 & 47 & -50 & 10 & 90 & 90 \\
\hline $\mathbf{5}$ & 47 & 70 & -50 & -5 & 90 & 90 \\
\hline $\mathbf{6}$ & 75 & 65 & -65 & 0 & 90 & 90 \\
\hline $\mathbf{7}$ & 70 & 70 & -70 & -5 & 90 & 90 \\
\hline $\mathbf{8}$ & 45 & 80 & -50 & -5 & 90 & 90 \\
\hline $\mathbf{9}$ & 25 & 70 & -70 & -5 & 90 & 90 \\
\hline $\mathbf{1 0}$ & 15 & 80 & -80 & -10 & 90 & 90 \\
\hline $\mathbf{1 1}$ & 45 & 80 & -70 & -10 & 90 & 90 \\
\hline $\mathbf{1 2}$ & 60 & 85 & -85 & -10 & 90 & 90 \\
\hline
\end{tabular}

According to the desired input angles, the output position and orientation of end effector for painting process at point 1 to point 12 can be obtained as ${ }^{0} \mathrm{~T}_{6}(1)$ to ${ }^{0} \mathrm{~T}_{6}(12)$.

$$
{ }^{0} \mathrm{~T}_{6}(1)=\left[\begin{array}{cccc}
0.030 & -0.985 & 0.171 & 50 \\
0.171 & 0.174 & 0.969 & 280.8 \\
-0.985 & -1.2 \times 10^{-5} & 0.174 & 220.9 \\
0 & 0 & 0 & 1
\end{array}\right],{ }^{0} \mathrm{~T}_{6}(2)=\left[\begin{array}{cccc}
0.353 & -0.707 & 0.612 & 178.2 \\
0.353 & 0.707 & 0.612 & 178.2 \\
-0.866 & -1.4 \times 10^{-5} & 0.499 & 314.2 \\
0 & 0 & 0 & 1
\end{array}\right]
$$


International Journal of Advances in Scientific Research and Engineering (ijasre), Vol 5 (12), December-2019

$$
\begin{aligned}
{ }^{0} \mathrm{~T}_{6}(3) & =\left[\begin{array}{cccc}
0.085 & -0.208 & 0.974 & 272.5 \\
0.018 & 0.978 & 0.207 & 57.9 \\
-0.996 & 0 & 0.087 & 224.2 \\
0 & 0 & 0 & 1
\end{array}\right],{ }^{0} \mathrm{~T}_{6}(4)=\left[\begin{array}{cccc}
0.119 & -0.282 & 0.951 & 270 . \\
0.023 & 0.959 & 0.281 & 78.2 \\
-0.992 & -0.011 & 0.121 & 213.7 \\
0 & 0 & 0 & 1
\end{array}\right] \\
{ }^{0} \mathrm{~T}_{6}(5) & =\left[\begin{array}{cccc}
0.184 & -0.732 & 0.655 & 172 \\
0.18 & 0.68 & 0.71 & 184.3 \\
-0.966 & -0.012 & 0.257 & 275.4 \\
0 & 0 & 0 & 1
\end{array}\right],{ }^{0} \mathrm{~T}_{6}(6)=\left[\begin{array}{cccc}
0.009 & -0.966 & 0.257 & 70.1 \\
-0.002 & 0.257 & 0.966 & 257 \\
-0.999 & -0.01 & 0 & 206.4 \\
0 & 0 & 0 & 1
\end{array}\right], \\
{ }^{0} \mathrm{~T}_{6}(7) & =\left[\begin{array}{cccc}
-0.02 & -0.94 & 0.338 & 90 \\
-0.084 & 0.339 & 0.937 & 245 \\
-0.996 & -0.009 & -0.086 & 193 \\
0 & 0 & 0 & 1
\end{array}\right],{ }^{0} \mathrm{~T}_{6}(8)=\left[\begin{array}{cccc}
0.19 & -0.708 & 0.68 & 188 \\
0.174 & 0.706 & 0.687 & 188 \\
-0.966 & -0.012 & 0.257 & 255 \\
0 & 0 & 0 & 1
\end{array}\right] \\
{ }^{0} \mathrm{~T}_{6}(9) & =\left[\begin{array}{cccc}
-0.074 & -0.43 & 0.899 & 237 \\
0.045 & -0.903 & 0.428 & 111 \\
-0.996 & -0.009 & -0.087 & 193.2 \\
0 & 0 & 0 & 1
\end{array}\right],{ }^{0} \mathrm{~T}_{6}(10)=\left[\begin{array}{cccc}
-0.164 & -0.268 & 0.949 & 240 \\
-0.054 & 0.963 & 0.263 & 65 \\
-0.985 & -0.008 & -0.172 & 181 \\
0 & 0 & 0 & 1
\end{array}\right], \\
{ }^{0} \mathrm{~T}_{6}(11) & =\left[\begin{array}{cccc}
0.007 & -0.711 & 0.7038 & 177.2 \\
-0.007 & 0.703 & 0.712 & 177 \\
-0.999 & -0.01 & 0 & 222.2 \\
0 & 0 & 0 & 1
\end{array}\right]{ }^{0} \mathrm{~T}_{6}(12)=\left[\begin{array}{cccc}
-0.078 & -0.868 & 0.489 & 122 \\
-0.154 & 0.496 & 0.855 & 210 \\
-0.985 & -0.008 & -0.172 & 182 \\
0 & 0 & 0 & 1
\end{array}\right]
\end{aligned}
$$

\section{ROBOANALYZER SIMULATION}

RoboAnalyzer simulation software is open source software, developed by S.K.Saha. It is 3D simulation software especially for robot technology study, which is mainly used for kinematics and dynamics simulation of robot or mechanical arm. Moreover, the software is simple and convenient to operate, and can generate the corresponding simulation graphics so as to understand the operation form of robot [8]. First of all, according to the test process, choose the type of robot in RoboAnalyzer software, and on the basis of the parameter values from Table1, modify initial D-H value of the software, thus robot simulation model is established. In this paper, only forward kinematic feature is used by RoboAnalyzer. The position and orientation of the robot forward kinematics results according to input joint angle point 1 to point 3 are shown in the following Figures. Figure 3 shows forward kinematics model of robotic arm due to D-H value by using RoboAnalyzer.

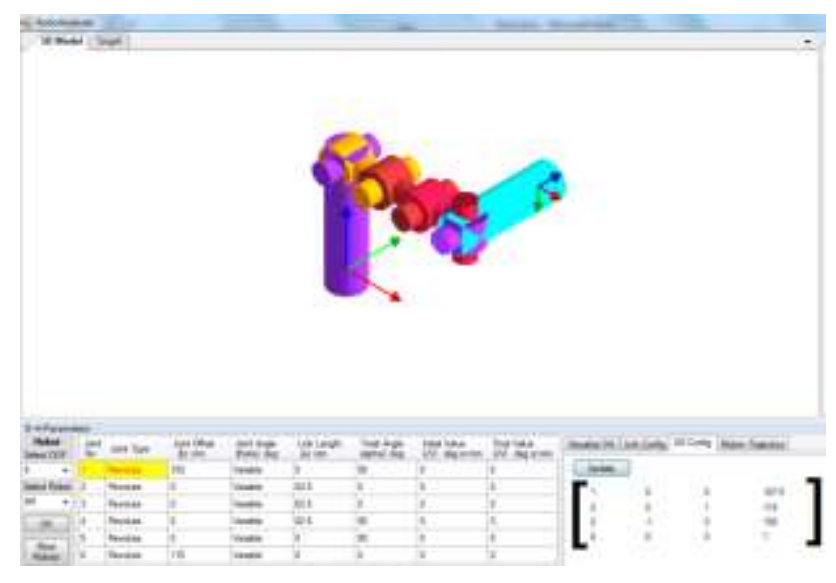

Figure 3. Forward kinematics model of robotic arm due to D-H value

When the angles of servos for point 1 due to input joint angle are applied, the position of end effector is $\mathrm{P}_{\mathrm{x}}=49.5 \mathrm{~mm}, \mathrm{P}_{\mathrm{y}}=$ $280.8 \mathrm{~mm}$ and $\mathrm{P}_{\mathrm{z}}=220.9 \mathrm{~mm}$. Figure 4 shows model of robotic arm from point 1 to point 2 and Figure 5 shows model of robotic arm from point 1 to point 3 . 

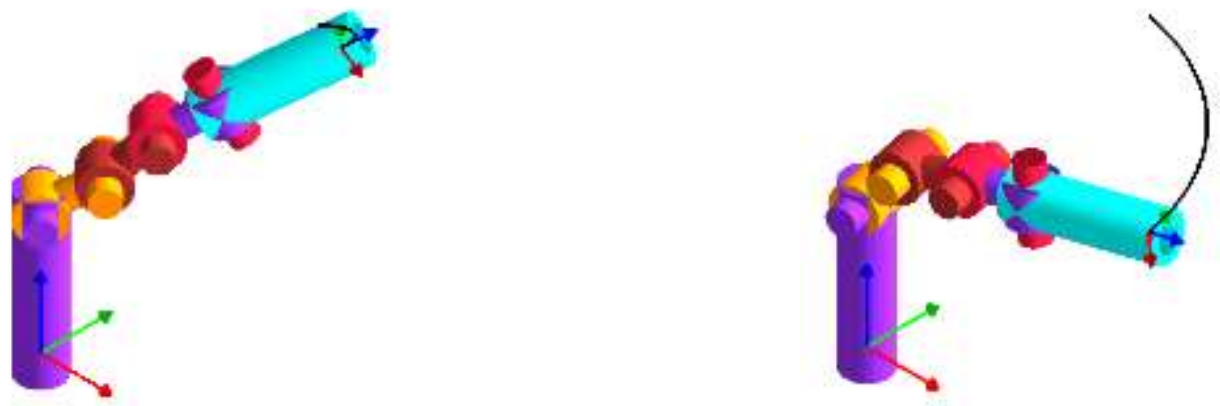

Figure 4. Robotic arm from point 1 to point 2 Figure 5. Robotic arm from point 1 to point 3

From the point 1 to the point 2 and the point 2 to the point 3 , the simulation time is designed as 1 s and the simulation step number is 10 , so the run trajectory of robotic arm from initial position to the end position on the $\mathrm{x}, \mathrm{y}$, and $\mathrm{z}$ direction is shown in Figure 6 and Figure 7. Figure 6 shows trajectory of robotic arm from point 1 to point 2 and Figure 7 shows trajectory of robotic arm from point 2 to point 3. From point 1 to point 3, the end-effector's position of X-axis is started at $49.5 \mathrm{~mm}$ and ended at $272.5 \mathrm{~mm}$. The results on $\mathrm{Y}$-axis are started form the $280.8 \mathrm{~mm}$ and ended at $57.9 \mathrm{~mm}$. Also, the results on Z-axis are started form the $220.9 \mathrm{~mm}$ and ended at $224.9 \mathrm{~mm}$ along zero to 10 steps. The highest position on $\mathrm{Z}$-axis is $314.2 \mathrm{~mm}$ occurred at point 2 .
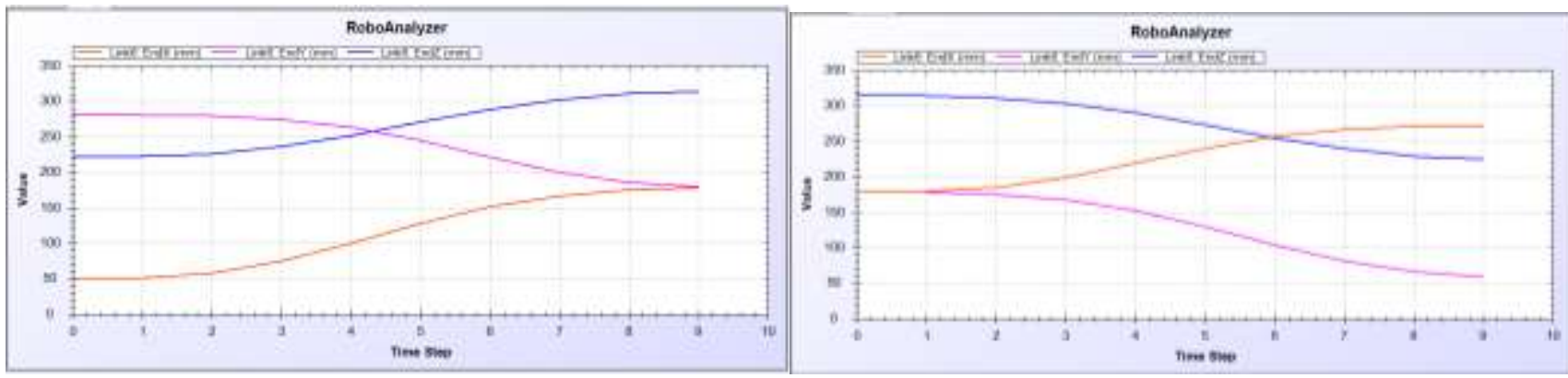

Figure 6. Trajectory of robotic arm from point 1 to point 2 Figure 7. Trajectory of robotic arm from point 2 to point 3

\section{CONSTRUCTION OF ROBOTIC ARM}

The robotic arm can be constructed with mechanical components, drive components and electrical and control components. The mechanical components of the robotic arm include base, shoulder, elbow and wrist linkage, connecting brackets, screws and nuts, and other minor accessories have been customized and fabricated according to the design. The mechanical components are fabricated with Aluminum 6061. The drive components of the robotic arm include PID 6221 digital servo motors with metal gear for revolute joints and Tower Pro MG 996servo motor with metal gear drive for wrist joints. All of the drive components have been purchased. The electrical and control components include 5V power supply, microcontroller and other accessories. Drive components of the robotic arm prototype are controlled via pulse width modulation signals generated from Arduino Uno microcontroller. Six degree of freedom articulated robotic arm model is shown in Figure 8.

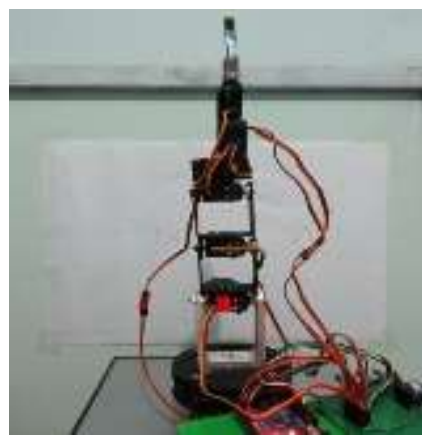

Figure 8. Six degree of freedom articulated robotic arm model

\section{PERFORMANCE TEST OF ROBOTIC ARM}

The experimental work on a six DOF articulated robotic arm is done by the given input angles of the motion before proceed with the programming. Firstly, the joint angles of each link are given as input parameters. After that, microcontroller generates the pulse with modulation (PWM) signals for each servo according to the joint angles from kinematic model. Then, kinematic model gives the Cartesian coordinates to desired arm position. Servo motors are then operated with PWM signals to 
achieve the desired position of the robotic arm. Photo taken during the performance test of robotic arm from point 1 to point 3 are shown in Figure 9 (a) to (c).

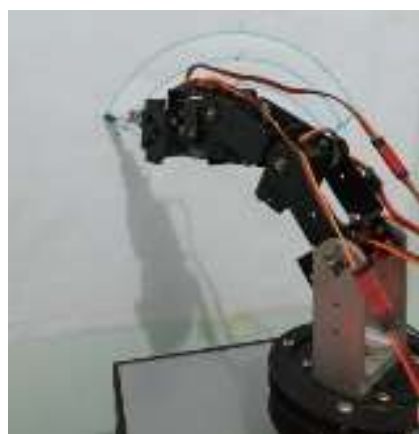

(a) Point 1

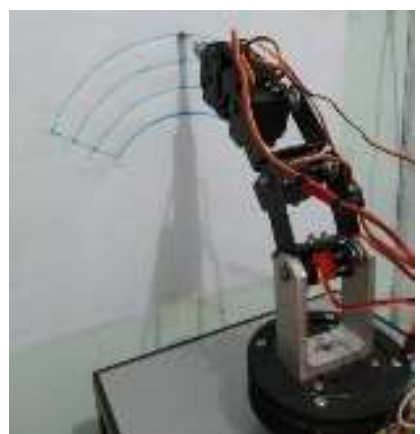

(b) Point 2

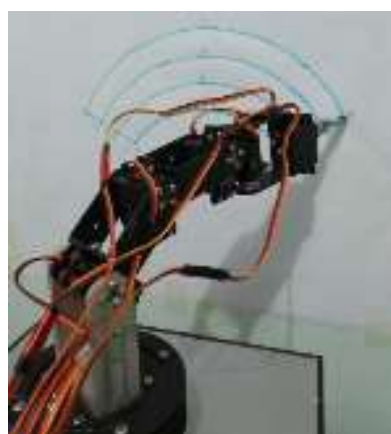

(c) Point 3

Figure 9 (a) to (c) shows photo taken during the performance test of robotic arm for point 1, point 2 and point 3 . From this Figure 9 (a) the angles of servos for point 1 due to input joint angle are applied, the position of end effector is occurred at $\mathrm{P}_{\mathrm{x}}=$ $50 \mathrm{~mm}, \mathrm{P}_{\mathrm{y}}=281 \mathrm{~mm}$ and $\mathrm{P}_{\mathrm{z}}=225 \mathrm{~mm}$. The position of end effector for point 2 is obtained $\mathrm{P}_{\mathrm{x}}=178 \mathrm{~mm}, \mathrm{P}_{\mathrm{y}}=178 \mathrm{~mm}$ and $\mathrm{P}_{\mathrm{z}}=$ $325 \mathrm{~mm}$ as shown in Figure 9 (b). And also, the position of end effector for point 3 is obtained $P_{x}=273 m m, P_{y}=58 \mathrm{~mm}$ and $P_{z}=$ 230mm as shown in Figure 9 (c).

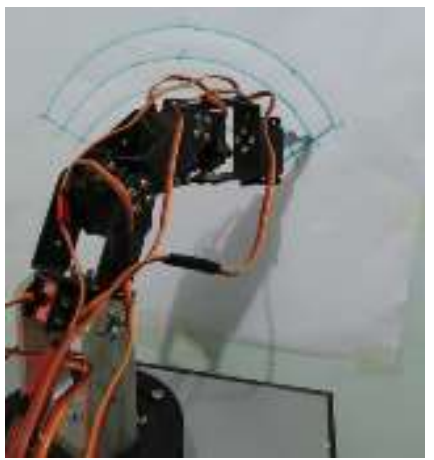

(d) Point 4

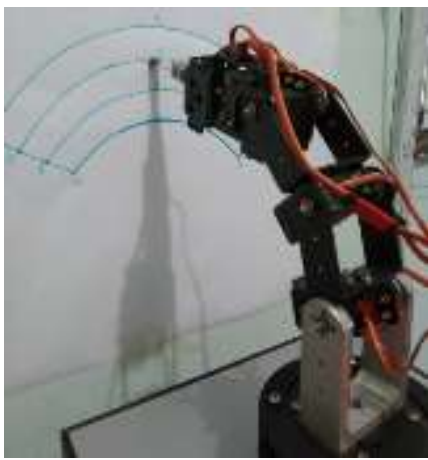

(e) Point 5

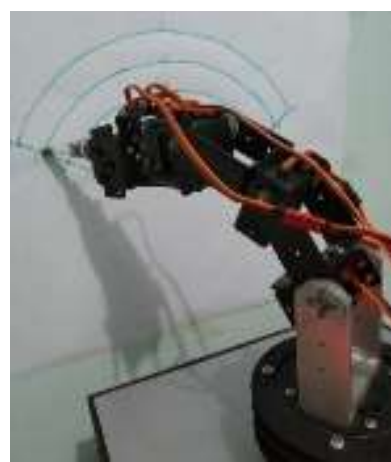

(f) Point 6

Figure 9 (d) to (f) shows photo taken during the performance test of robotic arm for point 4, point 5 and point 6 . From point 4 to point 6 , the end-effector's positions of Z-axis are $215 \mathrm{~mm}, 290 \mathrm{~mm}$ and $213 \mathrm{~mm}$.

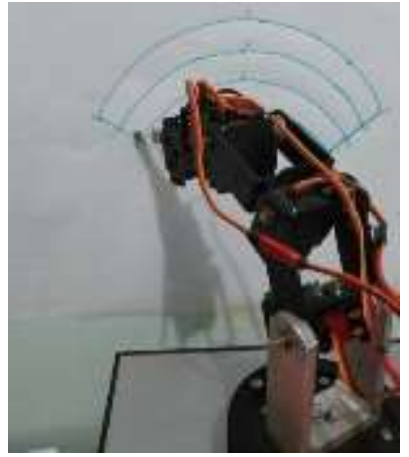

(g) Point 7

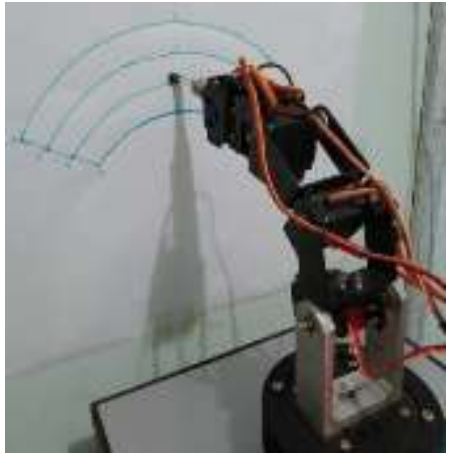

(h) Point 8

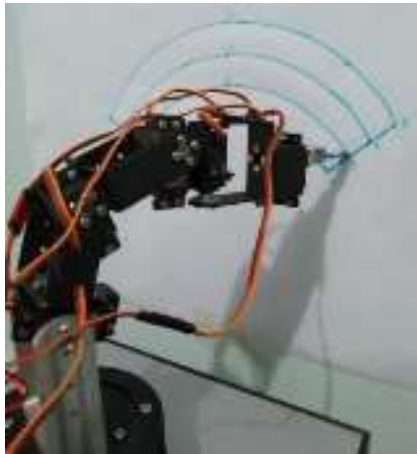

(i) Point 9

Figure 9 (g) to (i) shows photo taken during the performance test of robotic arm for point 7 , point 8 and point 9 . From point 7 to point 9 , the end effector's positions of Z-axis are $200 \mathrm{~mm}, 260 \mathrm{~mm}$ and $200 \mathrm{~mm}$. 
International Journal of Advances in Scientific Research and Engineering (ijasre), Vol 5 (12), December-2019

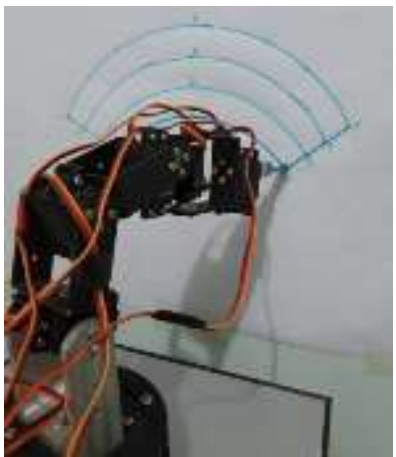

(j) Point 10

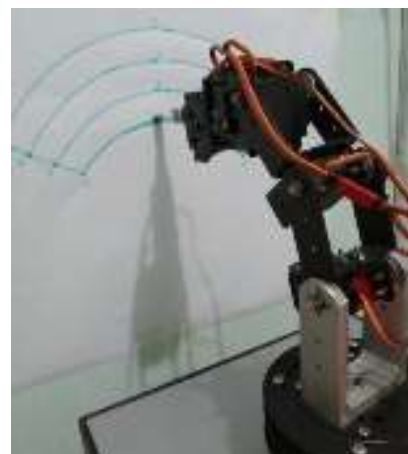

(k) Point 11

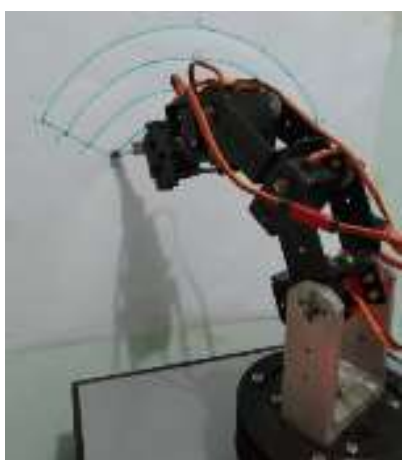

(l) Point 12

Figure 9. Photo taken during performance test of robotic arm from point 1 to point 12

When the angles of servos for point 10 due to input joint angle are applied, the position of end effector is $P_{x}=240 \mathrm{~mm}, \mathrm{P}_{\mathrm{y}}=$ $65 \mathrm{~mm}$ and $\mathrm{P}_{\mathrm{z}}=185 \mathrm{~mm}$ obtained as shown in Figure 9 (j). Figure 9 (j) to (l) shows photo taken during the performance test of robotic arm for point 10, point 11 and point 12 . The natures of robotic arm model from simulation result and performance test at any point are nearly the same.

\section{RESULT AND DISCUSSIONS}

In this section, forward kinematics is used to analyze kinematics behaviors of six DOF articulated robotic arm for the theoretical analysis. The results from the forward and inverse kinematics are presented. After testing the robotic arm, there is a little error occurred. The position of end effector in performance test is not exactly equal to the calculated result. This is due to the fact that feedback control law has not been taken into account in this research work. Table 3 shows the position tracking error of robotic arm.

Table 3. Position tracking error of a six DOF robotic arm for painting process

\begin{tabular}{|c|c|c|c|c|c|c|c|c|c|c|c|c|}
\hline \multirow{2}{*}{ Points } & \multicolumn{2}{|c|}{\begin{tabular}{c} 
Desired Position (mm) \\
\cline { 2 - 14 }
\end{tabular}} & \multicolumn{2}{|c|}{$\begin{array}{c}\text { RoboAnalyzer Simulation } \\
\text { Position (mm) }\end{array}$} & \multicolumn{2}{|c|}{$\begin{array}{c}\text { Experimental Position } \\
(\mathbf{m m})\end{array}$} & \multicolumn{3}{|c|}{ Error (\%) } \\
\hline 1 & 50 & 281 & 221 & 50 & 281 & 221 & 50 & 281 & 225 & 0 & 0 & 1.8 \\
\hline 2 & 178 & 178 & 314 & 178 & 178 & 314 & 178 & 178 & 325 & 0 & 0 & 3.4 \\
\hline 3 & 273 & 58 & 224 & 273 & 58 & 224 & 273 & 58 & 230 & 0 & 0 & 2.6 \\
\hline 4 & 270 & 78 & 214 & 270 & 78 & 214 & 270 & 78 & 215 & 0 & 0 & 0.5 \\
\hline 5 & 172 & 184 & 275 & 172 & 184 & 275 & 172 & 184 & 290 & 0 & 0 & 5.2 \\
\hline 6 & 70 & 257 & 206 & 70 & 257 & 206 & 70 & 257 & 213 & 0 & 0 & 3.3 \\
\hline 7 & 90 & 245 & 193 & 90 & 245 & 193 & 90 & 245 & 200 & 0 & 0 & 3.5 \\
\hline 8 & 188 & 188 & 255 & 188 & 188 & 255 & 188 & 188 & 260 & 0 & 0 & 1.9 \\
\hline 9 & 237 & 111 & 193 & 237 & 111 & 193 & 237 & 111 & 200 & 0 & 0 & 3.5 \\
\hline 10 & 240 & 65 & 181 & 240 & 65 & 181 & 240 & 65 & 185 & 0 & 0 & 2.2 \\
\hline 11 & 177 & 177 & 222 & 177 & 177 & 222 & 177 & 177 & 230 & 0 & 0 & 3.5 \\
\hline 12 & 122 & 210 & 182 & 122 & 210 & 182 & 122 & 210 & 187 & 0 & 0 & 2.7 \\
\hline
\end{tabular}




\section{CONCLUSION}

Forward kinematics, simulation and performance test of a six degree of freedom (DOF) articulated robotic arm are presented. Verification of kinematics of the robotic arm was done by means of theoretical, simulation using RoboAnalyzer and performance test. End effector positions of the robot forward kinematics results obtained from theoretical and simulation anayzes are similarly equal. According to the performance results, there is little error which is $\leq 5.2 \%$ in $\mathrm{z}$ direction. In $\mathrm{x}$ and $\mathrm{y}$ direction has no error. The position of end effector in performance is not equal to the desired position. Position tracking error of a six DOF robotic arm occur 5.2\% in vertical direction. Finally, it can be said that kinematic model can be used to control the six degrees of freedom articulated robotic arm autonomously, that is between -90 and 90 degrees, position and orientation of the desired location of tip of the end effector can be achieved by using open loop control system.

\section{ACKNOWLEDGMENT}

The author would like to gratefully acknowledge Dr. Ei Ei Htwe, Pro-Rector, Mandalay Technological University, for her kind permission to submit this paper. The author would like to thank Dr. Win Pa Pa Myo, Professor and Head, Mechanical Engineering Department, Mandalay Technological University, for her helpful, invaluable suggestions and comments.

The author would like to express the deepest gratitude to her supervisor Dr. Myint Thein, Professor, Mechanical Engineering Department, Mandalay Technological University, for his invaluable guidance throughout the entire process of this research work. This research work would not have been possible without his support.

The author would like to thank to her co-supervisor Dr. Htay Htay Win, Professor, Mechanical Engineering Department, Mandalay Technological University, for her helpful, invaluable suggestions and comments.

The author would like to also thank to her member Dr. Aung Ko Latt, Associate Professor, Mechanical Engineering Department, Mandalay Technological University, for his guidance, invaluable suggestions and comments.

The author especially appreciates and thanks all her teachers for support, and guidance during paper preparation. Finally, the author is deeply grateful to her parents, sisters and brothers who helped her.

\section{REFERENCES}

1. Qi Fei, Ping XueLiang, "The Analysis and Simulation of Robot Kinematics and Dynamics Based on RoboAnalyzer", International Journal of Emerging Technology and Advanced Engineering, Vol.5, Issue 4, April 2015.

2. Marizan Sulaiman, "Simulation and Experimental Work of Kinematic Problems for Kuka Kr 5 Sixx R650 Articulated Robot", International Journal of Energy and Power Engineering Research, 2013.

3. JamshedIqbal, Hamza Khan: Modeling and Analysis of a 6 DOF Robotic Arm Manipulator, 2012.

4. M. H. Korayem, "Design, Modeling, Implementation and Experimental Analysis of 6R Robot", IJE, Vol. 21, No. 1, February 2008.

5. Etienne Dombre, Wisama Khalil: Robot Manipulator, Modelling, Performance Analysis and Control, 2007.

6. Jorge Angeles, "Fundamentals of Robotic Mechanical Systems", Theory, Methods, and Algorithms, 3rd ed., Springer, 2007.

7. T.C. Manjunath: Kinematic Modelling and Maneuvering of a 5-Axes Articulated Robot Arm, 2007.

8. J. Robert Schilling: Fundamentals of Robotics Analysis and Control, 2005.

9. John J. Craig: Introduction to Robotics Mechanics and Control, Second Edition, 1955.

10. B.B.V.L. Deepak, D.R. Parhi: Design and Kinematiac Analysis of an Articulated Robotic Manipulator. 